\section{Philosophy of Chemistry}

\section{9-11 August 2011, Bogota, Colombia}

Each year, the International Society for the Philosophy of Chemistry organizes a symposium which gathers the leading researchers working on philosophy and foundational issues of chemistry. This year, the ISPC Conference will be held 9-11 August in Bogota, Colombia, at the Universidad de los Andes.

Lectures will be on such areas as foundational concepts, ontology, methods, ethics and aesthetics, as well as to the nature of chemical explanation, the relationship between chemistry and other sciences, historical aspects of chemistry, sociology and linguistics of chemistry and educational aspects. The special theme of ISPC 2011 will be the roots of Avogadro's hypothesis, its development and impact on chemistry and related fields, as well as its implications and prob- lems. Another special topic of interest will be the the relationship between mathematics and chemistry, its historical, development and the current state of this relationship which has given rise to the new chemical subfield of mathematical chemistry.

The 2010 ISPC meeting was held at the University of Oxford and in all previous years has alternated between North America and Europe. This year, (2011), the meeting is taking place, for the first time, in Latin America, thanks to the importance that philosophy of chemistry has gained in this part of the world. Let us make ISPC 2011 a meeting where scholars from Europe and the Americas come together and a place where the worldwide philosophy of chemistry community will strengthen its relationships.

\section{https://sites.google.com/site/intsocphilchem2011/home}

\section{Chemistry for Sustainable Agriculture \\ 15-18 February 2012, New Delbi, India}

The 2nd International Conference on Agrochemicals Protecting Crops, Health, and Natural EnvironmentRole of Chemistry for Sustainable Agriculture will be held in New Delhi, India, 15-18 February 2012.

The conference will provide a forum for scientists from different disciplines, industry, and other stakeholders to discuss the latest trends and discoveries in agochemicals and deliberate on important issues of agricultural research. The conference will comprise a number of plenary and keynote lectures by the world's leading scientists. Besides new copmpounds, new concepts and new uses, the conference will cover other traditional areas of research such as pest diseases,weed and resistance management, exploring biodiversity for botanical and biopesticides, genetically modified crops, and nutraceuticals, as well as research into effects on human health, risk management, ecotoxicology, and remediation strategies. The conference will also deliberate on other key issues such as analytical chemistry; pesticide residues in crops, food commodities, water, beverages; and changes in pesticide regulation.
The main themes of the conference are as follows:

- New Generation Synthetic and Natural

Agrochemicals

- Agrochemicals delivery systems towards occupational and environmental safety

- Pesticide and natural environment

- Pesticide resistance management.

- Biotechnology and Crop Protection-Current and Future Approaches

- Organic Approaches to Pest Management

- Pesticide Management for Human Safety and Food Security

- Pesticide Industry: Prospects and Constraints.

- Agrochemical Detection, Analysis and Quantification.

- Integrated Pest Management

- Nanotechnology and its Application in Agriculture and Health

- Chemical Fertilizers-Technologies for Improving Efficiency, Productivity and Reliability, NutrientBased Subsidy Policy

- Use of Geomatics in Farming System Research

\section{See Mark Your Calendar on page 36 for contact information.}

\section{www.apchne.com}

